\title{
Can welfare-rights advice targeted at older people reduce social exclusion?
}

\author{
SUZANNE MOFFATT* $*$ and GRAHAM SGAMBLER $\dagger$
}

\begin{abstract}
It is known that, in general, people of pensionable age have gained in income compared to other age groups in the British population over the last two decades, but that a substantial minority still experience relative poverty. This paper reports a small qualitative study into the effectiveness of a welfare-rights advice and acquisition service for men and women aged 6o or more years that was provided through a local primary health-care service. Additional financial and non-financial resources were obtained by accessing previously unclaimed state-welfare benefits. It was found that these significantly improved the participants' quality of life. Fourteen of the 25 participants received some type of financial award as a result of the service offered, with the median income gain being $£ 57$ (€84 or US \$IOI) per week. The impact of additional resources was considerable and included: increased affordability of necessities and occasional expenses; increased capacity to cope with emergencies; and reduced stress related to financial worries. Knowledge of and access to welfare-rights services also appeared to have a positive effect. It is argued that a level of material resources above a basic level is necessary for social relations and for accessing services and civic activities, and can reduce social exclusion among older people.
\end{abstract}

KEY WORDS - welfare rights, social exclusion, poverty, quality of life.

\section{Introduction}

The material wellbeing of Britain's pensioners has improved relative to those of working age in recent decades, but, as among working adults, older people have experienced increasing income inequality (Bardasi, Jenkins and Rigg 2002; Gilleard and Higgs 2005). Pensioners in the bottom income quintile are reliant upon the state for go per cent of their income, yet a substantial minority continues not to receive their full benefit entitlements (Victor 2005). In the United Kingdom (UK), 23 different types of state benefit are available to older people, and many are

* Institute of Health and Society, Newcastle University, Newcastle-upon-Tyne, UK.

$\dagger$ Unit of Medical Sociology, University College London, UK. 
interlinked in a complicated system of conditional entitlements (National Audit Office 2002). The scale of non-take-up is large but not exactly known, for it is difficult to estimate the proportion of older people who do not claim the benefits to which they are entitled. Recent estimates suggest that the proportion of older people not claiming the means-tested Pension Credit, which is designed to lift the poorest pensioners out of poverty, is between 34 and 42 per cent, and that the unclaimed amount is E. $1,630^{-2,370}$ million (Department for Work and Pensions 2006). ${ }^{1}$ High profile organisations like the Citizens' Advice Bureau (CAB), the local Age Concern organisations and Help the Aged have for decades run benefit take-up campaigns targeted at older people. ${ }^{2}$ Since the early ig9os, it has been recognised that providing benefits advice services for older people in a health-care setting, usually a primary health-care centre, can be highly effective and beneficial (Paris and Player 1993). This is largely because many older people have regular contact with primary care and because clinics and health centres are less stigmatising than the government's social security offices, most of which are spartan if not grim and are patronised mainly by unemployed people of working age (Coppel, Packham and Varnham 1999; Abbott 2002; Hoskins and Smith 2002; Hoskins et al. 2005).

A recent co-ordinated policy response to social and health inequalities by the Department of Health (Acheson I998), the Treasury (Wanless 2004) and the Social Exclusion Unit's 'Sure Start to Later Life' initiative (Social Exclusion Unit 2005) is promoting the uptake of social security benefits among vulnerable groups. Despite numerous high profile campaigns, however, the problem of the low uptake of state-welfare entitlements among older people persists (Department for Work and Pensions 2006). Studies have shown that older people have little knowledge of the welfare system and face numerous barriers when claiming benefits (Corden i999; Costigan et al. I999; Mayhew 2002), and that the poorest have very low expectations about their living standards (Scharf et al. 2006).

Low income, poor health and age have all been identified as causal factors for 'social exclusion', itself a contested concept (Silver I994; Atkinson 1998; Hills, Le Grand and Piachaud 2002; Social Exclusion Unit 2005). One general definition of social exclusion is 'being shut out, fully or partially, from any of the social, economic, political or cultural systems which determine the social integration of a person in society. Social exclusion may, therefore, be seen as the denial (or non-realisation) of the civil, political and social rights of citizenship' (Walker and Walker i997: 8). Whether social exclusion is a useful addition to the discourse on inequality is debated (Byrne 2005). Burchardt, Le Grand and Piachaud (2002) argued that social exclusion is a broad term that encompasses diverse views about

\section{CAMbridge}


its underlying causes. The most commonly recognised are individual behaviour and moral values; the vagaries of welfare policies, the entitlement rules and application and systems - in the round, the structure of the welfare state in late capitalism and a globalised economy; and discrimination and deficient social rights.

Different propositions about the causes of social exclusion derive from different views about individual agency. One emphasises the weak agency of the excluded (i.e. blaming the individual); a directly opposed view sees exclusion as the outcome of the economic, political and civil institutions that make up the welfare system. Scharf, Phillipson and Smith (2005: 77) have usefully applied the concept of social exclusion to older people. They argued that 'social exclusion can potentially represent a flexible and multi-dimensional tool for examining the degree to which older people in different environmental settings simultaneously experience various forms of disadvantage'. They operationalised their definition of social exclusion among older people as exclusion from: material resources; social relations; civic activities; basic services; and interactions with neighbours.

Among older people, interactions between ill-health and social exclusion are influential factors, for they may be mutually exacerbating. Social inequalities in self-reported ill-health increase in early old age (Chandola et al. 2007). Some 60 per cent of people aged 65 or more years have a long-standing illness (Office of National Statistics 200i), and a greater percentage of the lower socio-economic groups (Prescott-Clarke et al. I997). Research on people in mid-life has indicated that those with caring responsibilities are more likely to have low income in later life (Evandrou and Glaser 2004), and that women are particularly at risk, since most do not have a full state pension or an adequate occupational pension (Ginn 2003 $a, b$; Price and Ginn 2006). The difficulties of many of those in the poorest health are compounded by low income, not least because of the considerable costs associated with ill-health and disability (Argyle 2001; Smith et al. 2004).

This paper reports the findings of a qualitative study of the views of older people about the impact of welfare-rights advice (Moffatt et al. $2006 a$ ). The participants were drawn from the sample of people aged 6o or more years taking part in a randomised controlled trial (Mackintosh et al. 2006). The parallel studies examined the impact of additional material resources on the lives of older people, and explored the relationship between material resources and the other dimensions of social exclusion (Mackintosh et al. 2006; Moffatt et al. 2006a; Moffatt and Higgs 2007). This paper focuses on the questions: what impact did extra resources have for older people on low incomes and/or in poor health, and how effective 
is a welfare-rights service in increasing the incomes of low-income older people?

\section{Design and methods}

The qualitative study was concurrent with a pilot randomised controlled trial (RCT) that assessed the impact of welfare-rights advice provided through a general medical practice (viz. a National Health Service (NHS) primary health-care centre). All general practices in the adjacent conurbations of Newcastle-upon-Tyne and North Tyneside (North East England) were surveyed to ascertain the level of welfare-rights services currently offered (Mackintosh et al. 2006). Those without in-house or nearby services were invited to participate in the study and four general practices in the City of Newcastle-upon-Tyne agreed to participate. The practices were located predominantly, though not exclusively, in more deprived areas of the city. Three were located in the top io per cent of the most deprived electoral wards in England (two practices were in the top one per cent and ranked 3oth and 36th of the most deprived), and the fourth practice was ranked 3,774th (of the 8,414 electoral wards in England) (Department for the Environment, Transport and the Regions 200o). The qualitative study focused on the patient's experiences in both the intervention and control arms of the study that started in June 2002. The RCT recruited I 26 participants over five months.

The participants were interviewed on entry to the RCT using a face-toface structured questionnaire that examined physical and mental health, financial circumstances, psychological functioning and social wellbeing. They were randomly allocated to intervention and control arms. Those in the intervention group were given a welfare-rights consultation within two weeks of the baseline interview and re-interviewed with the structured questionnaire at six, 12 and 24 months; the control group received their welfare-rights consultation six months after the baseline interview and were followed up at six and I2 months. The difference of six months in the timing of the two groups' welfare-rights advice was a compromise between allowing sufficient time between the intervention and control arms for an observable effect and an ethically acceptable design (Moffatt et al. 2006a). A staff member of Newcastle-upon-Tyne City Council's Welfare Rights Service who had considerable experience of providing advice in primary care, particularly for older people, worked closely with the research team throughout. The officer took part in general practice briefings alongside members of the research team and delivered the intervention to each participant, which was a standard welfare-rights assessment, follow up

\section{CAMBridge}


work on claims, appeals and tribunals, and onward referrals to other services. $^{3}$

\section{Sampling}

Some iI7 (93\%) participants completed all stages of the data collection. The sampling frame was the 96 informants ( $76 \%$ of the RCT sample) who gave their consent to be contacted during their baseline interview for the RCT. The study sample was purposively selected on the basis of gender, age, general practice and participation in both intervention and control group. Sampling for the qualitative study did not take place until the outcome of the welfare-rights assessment was known, so it was also possible to include all possible outcomes: receiving additional financial assistance only; receiving non-financial assistance only; receiving both financial and non-financial assistance; and those not eligible for any additional resources.

\section{Data collection}

The 25 initial interviews took place between April and December 2003 in the participants' homes after their welfare-rights assessment, in ro cases with the respondent's partner present. Twenty-two follow-up interviews were undertaken between I 2 and 18 months later in 2005 (three individuals were too ill to take part). The interview schedules were semi-structured and covered: changes in circumstances as a result of welfare-rights advice; perceived impact of material and/or financial benefits; perceived impact on mental and/or physical health; perceived impact on health-related behaviours; perceived social benefits; and views about the associations between material resources and health. All participants agreed to their interview being tape-recorded, and they were transcribed in full. The duration of the interviews ranged from 35 to 120 minutes, with most lasting between 6o-75 minutes. Observational field notes were also taken.

\section{Analysis}

Data analysis followed the framework approach (Ritchie and Lewis 2003). Each of the transcripts was read and re-read, and a conceptual framework devised which was discussed at length with the researcher who carried out the structured interviews for the RCT. Coding was undertaken by one person (SM). Thematic categories were applied to each interview using the coding procedure in the NVIVO software package (QSR International 200o). The data were indexed and charted systematically and the resulting typologies discussed with other members

\section{CAMbridge}

\section{JOURNALS}


T A B L E I. Socio-demographic, housing and income attributes of the participants

\begin{tabular}{|c|c|c|c|}
\hline Variable and category & Number & Variable and category & Number \\
\hline \multicolumn{2}{|l|}{ Study group } & \multicolumn{2}{|l|}{ Sex } \\
\hline Intervention & I4 & Male & II \\
\hline Control & II & Female & I4 \\
\hline Mean age (years) & 75 & Age range (years) & $62-82$ \\
\hline \multicolumn{2}{|l|}{ Marital status } & \multicolumn{2}{|l|}{ Housing tenure } \\
\hline Married & I4 & Owner occupied & I6 \\
\hline Single & 2 & Rented & 8 \\
\hline Widowed & 9 & Rent free & I \\
\hline \multicolumn{2}{|l|}{ GP practice } & \multicolumn{2}{|l|}{ Council-tax band $^{1}$} \\
\hline GPI & 7 & Band A & I7 \\
\hline $\mathrm{GP}_{2}$ & 5 & Band B & 2 \\
\hline $\mathrm{GP}_{3}$ & 6 & Band C & 4 \\
\hline $\mathrm{GP}_{4}$ & 6 & Band D & 2 \\
\hline \multicolumn{2}{|c|}{ Months from assessment to interview } & \multicolumn{2}{|l|}{ Car ownership } \\
\hline Intervention & Io & No car households & I3 \\
\hline Control & 5 & Car owning households & $\mathrm{I} 2$ \\
\hline \multicolumn{4}{|c|}{ Value of additional income per week $(£)$} \\
\hline Mean & I83 & Mean & $29 \mathrm{I}$ \\
\hline Range & I3I-24I & Range & $206-622$ \\
\hline Median $^{2}$ & $\mathrm{I} 7 \mathrm{I}$ & Median $^{3}$ & 270 \\
\hline
\end{tabular}

Notes: I. Council-tax is the local authority domestic property tax and is calculated according to the estimated values of the property and the number of people living in it. Band A represents the lowest property value and Band D the highest. 2. The median weekly income of one-person pensioner households (before housing costs) in 2000/or in the UK was fir79 (Department for Work and Pensions 2002). 3. The median weekly income for two-person pensioner households (before housing costs) in $2000 /$ or in the UK was $£ 293$.

of the research team, 'a pragmatic version of double coding' (Barbour 2003). This method of organising the data allows the participants' circumstances, experiences and views to be compared within and across groups in a framework derived from their own accounts. The analysis and interpretation were therefore fully grounded in the data. Two kinds of internal validation were used, constant comparison (Silverman 2000) and deviant case analysis (Clayman and Maynard i995), since both methods are important for internal validation (Barbour 200I, 2003).

\section{Results}

Table I summarises the socio-demographic characteristics of the sample. The I4 participants in the intervention group had a longer interval

\section{CAMBRIDge JOURNALS}


T A B L E 2. Outcomes of the welfare-rights consultations

\begin{tabular}{|c|c|c|}
\hline Type of additional benefit & $\begin{array}{l}\text { Number of } \\
\text { recipients }{ }^{1}\end{array}$ & Value $(£)^{2}$ \\
\hline \multicolumn{3}{|l|}{ Financial (social security) benefits } \\
\hline Attendance Allowance (higher rate $£ 57.20$ ) & 7 & 362.10 \\
\hline Attendance Allowance (lower rate $£ 3^{8.30}$ ) & 3 & II 4.90 \\
\hline Severe Disability Premium/Allowance & I & 42.25 \\
\hline Carer's Premium & I & 20.25 \\
\hline Council-tax Benefit & 5 & $4 \mathrm{I} \cdot 5 \mathrm{I}$ \\
\hline Income Support/Minimum Income Guarantee/Pension Credit & 7 & I23.32 \\
\hline Housing Benefit & I & I5.7I \\
\hline Total & & 720.04 \\
\hline \multicolumn{3}{|l|}{ Non-financial benefits } \\
\hline Blue Badge & 4 & \\
\hline ‘Staywarm’ & 2 & \\
\hline Aids and adaptations & 3 & \\
\hline Number of participants & 25 & \\
\hline
\end{tabular}

Notes: Omitted from this table are one Disability Living Allowance ( $£ 30.30$ per week) and one Severe Disability Premium award (£23.30 per week) for a participant's son, and two Attendance Allowance awards for a participant's siblings ( $£ 76.60$ per week) not resident in the household. I. Some participants received more than one benefit. 2. Amount gained by household per week (Sept 2002-Sept 2003).

between their welfare-benefits consultation and interview (average I0.4 months) than the II in the control group (average 4.6 months). This was because the control group received their benefit assessment six months after the intervention group, leaving less time to collect the data. At the first interview, therefore, those in the intervention group had had more time to experience changes resulting from their welfare assessment, although the follow-up interviews allowed both the intervention and control group participants to describe the impact over I8 to 24 months. Although no couples or individuals had incomes below 6o per cent of the median national income, the UK Government's usual definition of low income (Barnes 2005), most were in the second or third lowest income quintiles. The housing and financial circumstances of the participants ranged from single pensioners with no occupational pension living in rented accommodation and entirely reliant on state benefits, to homeowner couples with occupational pensions and considerable savings. Most participants found it difficult to manage on their current level of resources, and most were in poor health with one or more chronic health conditions or were caring for a chronically ill relative.

Tables 2 and 3 summarise the outcome of the welfare-rights consultation for the participants and show that a wide range of financial and non-financial benefits were obtained. All participants in this study received 
T A B L E 3. Numbers that received additional financial and non-financial benefits

\begin{tabular}{lc}
\hline Type of additional benefit & Number \\
\hline No benefits awarded $^{1}$ & 7 \\
Received some type of award(s) $^{1}$ & I8 \\
Received only financial award(s) $^{2}$ & 7 \\
Received only non-financial award(s) $^{2}$ Received both financial and non-financial awards & 4 \\
Sample size $^{2}$ & 7 \\
& 25 \\
\hline
\end{tabular}

Notes: I. Four participants had received an award prior to the study. 2. One participant received an award just prior to the follow-up interview, 24 months after the start of the study.

the basic state pension, although the amount varied, particularly for women, most of whom had not made full contributions throughout their lives. The Attendance Allowance ${ }^{4}$ was claimed more than any other single benefit, reflecting the poor health and high care needs of many in the sample. By the end of the follow-up period, I5 participants had received a financial award, the amount per week ranging from $\oint_{\mathrm{IO}}\left(€_{\mathrm{I}}\right.$, or US\$I $)$ to $\mathcal{E}_{\mathrm{IOO}}\left(€_{\mathrm{I} 48} 8, \$ \mathrm{I} 78\right)$, giving an increase in income from four to 55 per cent. The median weekly income gain was $£ .57$ (€84, \$IOI). Several participants received non-financial benefits, in addition to a range of aids and adaptations. These included the 'Blue Badge', a scheme to enable those with mobility problems to park their (or their carer's) vehicle in disabled parking bays, and 'Staywarm', a UK national energy purchase scheme for those aged 60 or more years, which provides a fixed weekly grant for fuel irrespective of actual consumption.

That only one person received a new 'Housing Benefit' - a meanstested social security benefit administered by local authorities for people on low incomes to help with rent payments-deserves some comment. This must be attributed to the proactive work of Newcastle City Council Welfare Rights Service, which regularly undertakes targeted Housing Benefit uptake campaigns in the city. Eighteen of the 25 participants received some sort of benefit as a result of this welfare-rights intervention. Of the seven participants who did not receive an award as a result of the present study, four had already received awards with assistance from other services (e.g. a blind and partially-sighted advice service and drop-in centres). Only one participant had obtained a state welfare benefit without any such assistance (Table 3). By the follow-up interview, all but one participant (Case 24) had received the additional resources for between I7 and 3I months. Welfare-rights advice was viewed positively by all participants irrespective of outcome. For those who received additional financial resources, the impact was considerable. Four categories of impact are now described. 


\section{Raised ability to buy necessities}

All the recipients used their additional money to pay for necessities, without which their ability to participate in daily activities such as getting around, buying decent food, engaging in social activities, paying bills and obtaining extra help had been restricted. As Table 4 details, many increased their spending on transport, which the participants' narratives indicated was crucial to their social participation. As a group, the participants were generally in poor health and many had mobility problems that impaired their ability to get around for essential activities. Just over onehalf of the respondents had no car. The additional resources enabled more use of both private and public transport, but, for many, personal mobility difficulties limited the use of buses and trains. For those without cars, being able to afford taxis for shopping, visiting friends and engaging in activities was life transforming. Mr MacDonald, a keen bowls player, described the devastation he felt when he became unable to drive and the importance to him of being able to continue his leisure activities:

I'd had a car for 45 years and it was like cutting my right arm off. Now, if I want to go out and I don't want to go by bus, I just get into a cab: that's the difference it makes. I am not worried about it if I want to go anywhere.

Among the participants who drove, a constant theme was their reliance on the car for almost every activity they engaged in outside their homes. Thoughts of giving up the car filled many with a sense of dread. Some participants were unable to take full advantage of their cars for anything other than essential activities because of the high cost of petrol. Following the additional income, the participants spoke about being able to buy petrol for trips to the countryside or to visit friends and relatives a distance away. Many participants acknowledged the positive impact this had on their wellbeing, particularly in cases of serious illness. Mrs O'Hara cared for her seriously ill husband and described the difficulties she faced on a low income, particularly having no resources for the outdoor activities that they had always enjoyed. With the additional income, they were now able to engage in pleasurable activities, even some they did on the 'spur of the moment':

We were quite depressed last month ... now we can afford petrol to go up the coast in the car. A tank full of petrol if we feel like it ... we cheered ourselves up ... whereas it would have been another miserable day, it did us good.

Better access to transport, whether taxis or private cars, increased travel mobility and that enabled the participants to engage in activities more frequently and in some that had previously been impossible. Without this engagement, they would have been more socially isolated, 
T А в L E 4. Impact of additional financial resources at first and follow-up interview shown by proportion of income increase

\begin{tabular}{|c|c|c|c|c|c|c|c|c|c|c|c|c|c|c|c|c|c|c|c|c|}
\hline \multirow[b]{2}{*}{$\begin{array}{l}\text { Case } \\
\text { no. }\end{array}$} & \multirow[b]{2}{*}{ Sex } & \multirow[b]{2}{*}{$\begin{array}{l}\text { Age } \\
\text { (yrs) }\end{array}$} & \multirow[b]{2}{*}{ 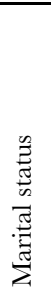 } & \multirow[b]{2}{*}{ 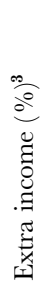 } & \multirow[b]{2}{*}{ 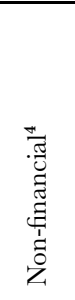 } & \multicolumn{6}{|c|}{ Able to buy necessities } & \multicolumn{6}{|c|}{ Able to pay occasional expenses } & \multicolumn{3}{|c|}{ Coping better ${ }^{6}$} \\
\hline & & & & & & 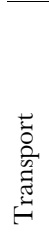 & 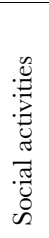 & ت & 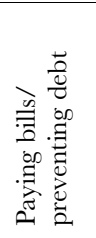 & 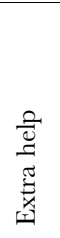 & 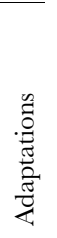 & 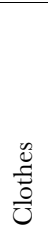 & 莺 & 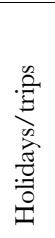 & 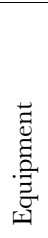 & 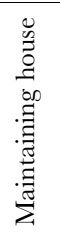 & 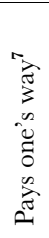 & 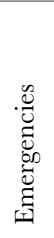 & 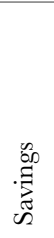 & 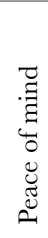 \\
\hline 3 & $\mathrm{~F}$ & 72 & W & 55 & & $\checkmark$ & $\checkmark$ & $\checkmark$ & $\checkmark$ & & & & + & + & + & & + & & + & $\checkmark$ \\
\hline $\begin{array}{l}\text { I7 } \\
17\end{array}$ & $\mathrm{~F}$ & 84 & W & $5^{2}$ & & $\checkmark$ & & $\checkmark$ & & & $\checkmark$ & & $\checkmark$ & + & $\checkmark$ & & & & & $\checkmark$ \\
\hline I4 & $\mathrm{F}$ & 82 & W & $5^{\mathrm{I}}$ & & $\checkmark$ & $\checkmark$ & $\checkmark$ & $\checkmark$ & + & & $\checkmark$ & $\checkmark$ & & + & & + & & $\checkmark$ & $\checkmark$ \\
\hline 4 & M & 74 & M & 33 & & $\checkmark$ & + & $\checkmark$ & & & & + & $\checkmark$ & & + & & & & $\checkmark$ & $\checkmark$ \\
\hline I5 & $\mathrm{F}$ & 62 & $\mathrm{M}$ & $3^{\mathrm{I}}$ & & + & & + & + & + & & $\checkmark$ & & + & $\checkmark$ & & + & $\checkmark$ & $\checkmark$ & $\checkmark$ \\
\hline 2 & $\mathrm{~F}$ & 74 & M & 22 & A, B & $\checkmark$ & & + & & + & & & & & & & & & & $\checkmark$ \\
\hline $5^{1}$ & $\mathrm{M}$ & 75 & M & 2I & B & $\checkmark$ & $\checkmark$ & & + & & & & & $\checkmark$ & + & & & & + & $\checkmark$ \\
\hline I & $\mathrm{M}$ & 75 & M & I9 & & $\checkmark$ & $\checkmark$ & + & & + & & & & $\checkmark$ & & & + & & & \\
\hline 7 & $\mathrm{M}$ & 75 & M & I8 & B & $\checkmark$ & $\checkmark$ & & $\checkmark$ & & $\checkmark$ & & + & $\checkmark$ & + & & + & & & $\checkmark$ \\
\hline $12^{1}$ & $\mathrm{M}$ & 79 & M & I8 & B & $\checkmark$ & $\checkmark$ & & & + & & & & $\checkmark$ & & & & & & \\
\hline $22^{2}$ & $\mathrm{~F}$ & 78 & M & II & $\mathrm{C}, \mathrm{S}$ & $\checkmark$ & & & & $\checkmark$ & & & & & & & & & & $\checkmark$ \\
\hline IO & $\mathrm{M}$ & 65 & M & 7 & & $\checkmark$ & $\checkmark$ & & $\checkmark$ & & & & & $\checkmark$ & & & & $\checkmark$ & $\checkmark$ & $\checkmark$ \\
\hline $9^{2}$ & $\mathrm{~F}$ & $8 \mathrm{I}$ & W & 7 & $\mathrm{~A}, \mathrm{~S}$ & $\checkmark$ & & & & & & & & & & & & & & $\checkmark$ \\
\hline $\mathrm{II}^{2}$ & $\mathrm{M}$ & 77 & M & 4 & & & & $\checkmark$ & $\checkmark$ & & & & & & & & & & & $\checkmark$ \\
\hline $24^{5}$ & $\mathrm{~F}$ & 74 & W & 20 & & $\checkmark$ & $\checkmark$ & $\checkmark$ & $\checkmark$ & & & $\checkmark$ & & & $\checkmark$ & & $\checkmark$ & & $\checkmark$ & $\checkmark$ \\
\hline
\end{tabular}

Notes: I. Full financial award not received at time of first interview. 2. No follow-up interview for reasons of ill-health. 3. Extra financial resources as a proportion of baseline income. 4. Non-financial awards: $\mathrm{A}=$ Aids and adaptations, $\mathrm{B}=$ Blue badge, $\mathrm{C}=$ Community-care alarm scheme (telecare device), $\mathrm{S}=$ 'Staywarm' scheme. 5. Received additional resources just prior to follow-up interview, 24 months after study started. 6 . Capacity to cope with crisis. 7. Gifts/treating family/paying their way. $\checkmark$ mentioned at first interview. + mentioned at follow-up interview.

\section{CAMbridge JOURNALS}


lonely and depressed. As well as positively enhancing mobility, the additional resources enabled the participants to maintain social activities and social networks, which is often difficult for those with chronic health problems. Mrs Parks described well how, following the death of her husband, being short of money had stopped her taking part in her social mainstay:

I was living on the bare pension ... it doesn't leave you much for entertainment, and I couldn't go very far because ... that's why I stopped going to the [name] Association. ... When they started to go away for weekends and different places for reunions and whatnot, well I couldn't go because I couldn't afford to go. You see, now I could, it makes that difference. It's not a lot but [makes] just that little bit difference, between not being able to afford anything above normal, to having a little bit of enjoyment and a little bit of entertainment. It's marvellous the difference it makes.

The participants mentioned various activities that they were able to engage in more frequently, re-start or begin afresh with the additional benefit income. These included visiting relatives more often, participating in choirs, bowling and social clubs, and walking in the countryside. Overall, the participants talked about a renewed ability to enjoy their leisure time. None of the mentioned activities required considerable resources. Despite this, the limited incomes that people were living on and the other demands on their income (food, heating, utility bills and home maintenance) meant that leisure activities had had low priority. The activities that facilitated enjoyment, social participation and positive physical and mental wellbeing had been beyond the reach of many, so that prior to receiving the benefit income, most led a marginal, isolated existence. The narratives clearly illustrated how the flow of material assets is crucial for a healthy flow of social assets or capital, an issue to which we will return.

Buying healthier and better quality food was mentioned by several participants, especially but not exclusively by those on the lowest incomes. Many participants mentioned that they would like a healthier diet, by which they usually meant lean meat, fresh fish and fresh fruit and vegetables. Some had been advised to change their diets for health reasons, but all the participants mentioned the high cost of healthier food; many could afford only what they regarded as less healthy but cheaper items. By the time of the follow-up interview, the participants had received the additional resources for a considerable time. Many mentioned that they had a healthier diet, particularly through being able to afford better quality foods and no longer buying the cheapest every time. Interestingly, several people mentioned that they were now able to stock certain items for use during ill health or severe weather: they were no longer obliged to go to 
the shops every day. Mrs Lewis explained very well how she used the additional income:

It [Attendance Allowance] has made a big difference, because it means that I haven't had to skimp so much on buying the groceries. And being as I've now got to buy fruit and things like that, which I never used to buy before ... because I've got it from the doctors that I've got to lose weight. It's helped me to be able to get me the extra bits that we need, where it would have been more difficult without that.

Housework, shopping and gardening were becoming increasingly difficult for many of the participants through health problems. By the followup interview, several were paying for extra help with these tasks. Such 'low-level' assistance has been identified as crucial to maintaining older people's ability to remain living independently in their own homes (Clark, Dyer and Horwood 1998). Many services hitherto provided by the 'home help' and other personal social services in the United Kingdom are now reserved for older people in 'significant' need. Several of the participants in this study required help with some daily tasks but could 'manage' without formal assistance from social services. Mrs MacLeod described the arrangement that she had made with a neighbour after receiving her benefit entitlement:

Well it makes me independent, doesn't it? You see my next door neighbour ... she's a young lady and she's smashing ... she comes in every week and I pay her ... it's a business deal, it's on a proper footing, it's not just neighbourly. ... Not only that, you feel independent ... you can do things for yourself, and that's a great boost when you get a bit older. ... It gives you a bit of a boost to your self-confidence I think ... you know [it] helps, it keeps the depression off a bit to know you can do things for yourself.

\section{The greater ability to afford occasional expenses}

Table 4 shows that a wide range of 'occasional' expenses was purchased as a result of the additional income. Some expenditure was for 'one off' replacements of items such as washing machines, refrigerators or televisions. Living on a fixed income, with little in the way of savings, meant that replacing most items was a cause of anxiety. Most mentioned that they would rather go without than slide into debt to pay for a replacement item. Mrs O'Hara explained her and her husband's difficulties:

It's when you want to put another coat of paint on or when you need to replace your bed sheets. They don't last forever, and they're not cheap. When you've got used to just your old-age pension and there isn't a lot of extra spare cash, it's all those things you have to think about.

\section{CAmbridge}


Several participants said that weekend trips and short holidays had been made possible by the extra income. Some might regard these items as 'luxuries' and even a frivolous use of state benefits, but careful consideration of the realities of life on low incomes suggests that these activities are highly beneficial and have a positive impact on wellbeing. The trips were usually modest affairs of two to four days; one participant went to Scotland for four days, her first holiday in 30 years. Those who did manage to go on short trips looked forward to them immensely, partly because they were a break from the general routine. The trips obviously raised the spirits of many.

Some participants were enjoying being more fully engaged with family, friends and wider society through their increased capacity to reciprocate in various ways, particularly by the time of their follow-up interview. This was evident in their accounts of being able to pay their way or to buy gifts for family and friends, sometimes to show gratitude for help received. The social significance of reciprocation for many older people should not be under-estimated. Many respondents described feeling marginalised by their families, friends and society at large because of their low incomes or ill-health (or both). Being able to reciprocate in normal social roles was highly regarded. One woman participant said, 'I used to feel terrible getting lovely presents from them [family, particularly grandchildren] and I couldn't afford very much [for them], but now I can and I love it'. Another woman expressed the same sense of wellbeing: 'I have two good friends who are very helpful so I buy them some boxes of chocolate or something like that you know, just to show my appreciation'.

\section{Capacity to cope with future crises}

Uncertainties about the future were regularly mentioned, and money worries were a constant source of anxiety. The participants talked about the problems that the onset of illness or the worsening of existing conditions would bring. Concerns about ill health and money were particularly acute for those with scant savings or assets. Prior to receiving the additional income, many participants were, in their words, 'just getting by', with no prospect of putting money aside for the future. With the additional resources, however, some said that they could save up for items they required, or increase their savings. One man explained, '[the extra benefit] is a nice handy little nest egg that would cover almost any emergency, well not almost any, but the minor emergencies'.

Several participants, both homeowners and those living in rented accommodation, were worried about the suitability of their accommodation

\section{CAMBridge}


in the future and the crises that further health problems might precipitate. Concerns were voiced about the onset or exacerbation of health conditions that would make managing stairs, gardens, cleaning and household maintenance increasingly difficult. Some participants discussed the possible need for more suitable accommodation, and were aware that such housing existed. Homeowners generally felt that more suitable accommodation was completely out of their reach because of the price differential between their home and purpose-built accommodation; those in rented accommodation (all local authority) believed that more appropriate accommodation would be available only for those who were less able than themselves. Non-financial housing issues were beyond the remit of the welfare-rights advice service, but the participants raised concerns about the suitability of existing accommodation for some older people and the lack of available alternatives for those on low incomes.

\section{More peace of mind}

The participants' narratives highlighted the daily stresses and strains of living on fixed low incomes. Financial worries were a constant source of anxiety, either because the participants could not afford necessities and one-off payments, or would not have sufficient in a crisis. The narratives richly exemplified what people did without to avoid getting into debt: foregoing a healthy diet; not having the house heated to a comfortable temperature; not buying new shoes or clothes when required; and not going out with family or friends. The list of privations was long. We do not suggest that the additional resources transformed the participants' lives to the extent that they had no continuing worries, but their accounts suggest that constant, nagging, money worries were considerably reduced. As Table 4 shows, most participants reported greater 'peace of mind' - the phrase was repeated often during the interviews. Having more (not necessarily adequate) money generated a tangible sense of wellbeing, as was still remarked upon at the follow-up interviews, suggesting that the effects were long lasting.

Perhaps the most powerful account of the difference that the full benefit entitlement had made came from a woman who for many years had been struggling to manage on the basic state pension. She had no idea about the benefits to which she was entitled, and had even been asked to return an Attendance Allowance benefit following the death of her husband (whom she had nursed at home), even though she had never claimed the allowance. There are still many older people, particularly women, living on the basic state pension unaware of the benefits that

\section{CAMBridge}


they could claim (Toynbee 2004). Mrs Parks described well the impact of having her full benefit entitlement:

You are not waiting in terror or in horror for the next [bill] to come through the door because it might mean you are going to be strapped again. I had enough of that when I was younger.

\section{Views on the relationship between money and health}

Given the well-established relationship between socio-economic position, resources and ill-health (Marmot and Nazroo 200 ; Chandola et al. 2007), it was important to examine the discourse about the relationship between money and health. Two main issues were identified from the narratives. The first concerned the specific relationship between additional money and the recipient's health, and the second referred to the general relationship between money and health. Regarding the first, the response was unequivocal that extra money or resources has no effect whatsoever on an individual's health. Poor health was attributed to specific diseases or disorders, family history or fate, all of which were seen as immune to the effects of money. Mrs Carruther's views were typical: 'I think it doesn't matter how much money you've got, if your health is going to deteriorate then it will deteriorate'. Most participants had at least one chronic condition and believed that because of these conditions and their age, additional money would have no effect. No one expected any improvements in their health as a result of additional resources, but some linked the impact of the intervention to improved ways of coping with their conditions, and explained how the extra resources helped. An exchange between the interviewer and Mrs Juniper was particularly revealing:

Mrs Juniper: I've got so much wrong with me my dear I don't think anything affects it. I suppose the fact that I have a more positive outlook on life now I've got a little bit more money ... and I suppose that can affect your health, but there isn't anything that money can buy that would make me any better. ... I certainly don't get the depressions that I used to get.

Interviewer: Why would you say that is?

Mrs Juniper: Well, I don't know. It's just generally not having to worry about money anymore. It's so nice to be able to feel you can splash out a little bit.

Interviewer: So if I asked you what effect having this extra has had for you, thinking in terms of health in a very broad sense, physical health as well as mental health, what would you say?

Mrs Juniper: Well, it just ... it's difficult to explain really. I've still got all these things wrong with me, but they don't seem to bother me as much now as they did, I don't know, you know I feel a lot happier about my life since I got that extra money. It has made a difference, a real difference. 
This narrative indicates that being more able to afford daily necessities, to use transport, to keep up with friends and family and to maintain leisure activities did not directly alter health, but gave an increased capacity to cope with ill health. The participants became more fully engaged in the more enjoyable and fulfilling aspects of life and had fewer immediate financial worries.

Although no one expected their own health to improve, most participants believed that there was a relationship between resources and health. This was usually couched in terms of being able to afford to eat well, pay bills and live in a comfortably heated home. Many respondents had previously had difficulties meeting these basic needs and spoke convincingly from experience. Others, like Mrs Wright, were aware of the privations experienced by other older people and empathised with those who had insufficient money:

If you've got somebody who is just on the basic pension, because there is an awful lot who haven't had pensions from work or anything [and] that didn't save, didn't know about having to ... they may not have enough to cope, and it's pretty obvious when you hear about them dying of hypothermia. ... There was something on the radio yesterday that this is the worst area in the country for old people dying of hypothermia and we're the worst-off people in the country - so many people on the dole, on benefits. It makes you wonder if people haven't got the money and they're going to miss out on either food or heat.

Overall, the study participants were clear that having additional resources would not improve their health conditions as such, but their accounts indicated that they made coping with particular health conditions and day-to-day living easier.

\section{Discussion}

The key question that has been addressed in this study is the impact upon older people on low incomes and/or in poor health of receiving additional resources. Analysis of the responses from the relatively small sample has indicated several ways in which supplementary finances improved the recipients' lives - helping them meet essential day-to-day expenses, increasing the capacity for one-off expenditures, increasing savings and coping with emergencies. We argue that this had a positive impact on personal wellbeing and that the overall effect was to increase independence and participation in society; in other words, it reduced social exclusion. Another way that this can be construed is that adequate resources are part of the citizenship rights of older people (Higgs 1997;

\section{CAMBridge}


Craig 2004), although the citizenship-rights discourse has recently been somewhat superseded by a social exclusion discourse (Hills and Stewart 2007). However the issue is conceptualised, the participants' narratives were replete with examples of how a modest increase in the flow of material assets brought an increase in social assets or capital. Reference to 'flows' of material and social assets here is deliberate. Assets conducive to longevity, health and wellbeing - not only material and social, but also biological, psychological, cultural and spatial (Scambler 2002) - are neither best studied through cross-sectional investigation nor readily quantifiable. First, they can come and go: assets can increase over a short period, as in this study, or decrease just as rapidly. Secondly, they continuously interact, as this study has exemplified. Thirdly, they may compensate for each other as far as health outcomes are concerned: a loss of material assets might be made good by a gain in social assets and vice-versa. Finally, studies oriented to the lifecourse suggest that specific assets may be especially relevant for certain conditions at particular periods of the lifecourse; for example, the need for additional resources in later life to offset the requirements of a disability or health condition when living on a fixed and relatively low income.

Caution is required when interpreting the conclusions of a qualitative study with a small sample (Mays and Pope 2000). One must ask to what extent the findings can be generalised to other settings or contexts. Methodologically, we have followed best practice in fieldwork, analysis and interpretation (Seale 1999; Mays and Pope 2000; Barbour 200I, 2003). At the 24-month follow-up, we had the opportunity to obtain more qualitative data from a further 2I participants in the RCT who had received additional financial resources which confirmed the findings reported here (Moffatt et al. 2006b). Ritchie and Lewis (2003: 269) commented that, 'It is at the level of categories, concepts and explanations that generalisation can take place'. We suggest that the reported data indicate that additional resources for those on low incomes are likely to reduce social exclusion and that the albeit limited literature on poverty and social exclusion among older people backs up this claim. The findings of the recent United Kingdom Poverty and Social Exclusion Survey (PSE Survey) offer an interesting point of comparison with our findings (Pantazis, Gordon and Levitas 2006). Not only has its results confirmed that a substantial minority of older people are in relative poverty, for i8 per cent reported that their incomes were insufficient to avoid absolute poverty, 2I per cent said their incomes were below the overall poverty threshold level, and 27 per cent had incomes below the overall poverty threshold level (Patsios 2006), but it has also provided evidence on flows of social assets or capital. According to the PSE Survey, poverty is a major 
cause of pensioner exclusion, although not of course the only one. The conclusion from one analysis of the data was that:

Many pensioners - particularly poorer, older and single ones - are excluded from social relations because they cannot afford to participate in common social activities, are socially isolated, they lack potential social support, do not engage in civic affairs, or are socially confined. ... Poverty is clearly a major cause of pensioner exclusion - it is associated with restricted utility service use, increased debts, inability to access elderly services (home helps, meals-on-wheels, etc), inability to participate in common social activities and increased confinement (Patsios 2006: 452).

Poverty, deprivation and social exclusion are inextricably linked. Reminding us of the derivation of the concept of relative poverty, Patsios suggests that poverty should be viewed as 'both material deprivation and the exclusion from social opportunities that makes it possible for many older people to take part in the activities that are deemed customary and "necessary" in their community" (2006: 543). Phillipson and Scharf (2004) have reviewed the impact of policies aimed at reducing poverty and social exclusion among older people. They pointed to the success of recent $\mathrm{UK}$ government policies in reducing the proportion of older people in both absolute and relative poverty, but concluded that 'the impact of policies on social exclusion has been uneven ... it has been less successful in challenging inequalities which are carried through into old age and which reflect the experiences of particular birth cohorts and groups within these cohorts' (2006: 8). Also pertinent to this discussion is Gordon et al.'s (200o) distinction between 'individual exclusion' and 'collective exclusion'. The former refers to services being unaffordable, the latter to services being unavailable or unsuitable. The PSE Survey results indicated that when individual (affordability) and collective (availability) exclusion are combined, poorer pensioners were in general much more likely to be excluded than non-poor pensioners from every major public-sector welfare. Such exclusion was even more marked for privately-purchased services. The study reported here has shown that increasing resources could reduce social exclusion among a small group of older people. This may apply to many older people in similar circumstances.

Also relevant to our discussion is the recent work that has systematically assembled evidence on the health needs of older people in England, and the minimal costs of meeting them (Morris et al. 2007). A minimum income for healthy living was derived from extensive evidence on diet and nutrition, physical activity, housing, medical care entailing costs, psychosocial relations and social inclusion. The calculated minimum income for healthy living was $5^{0}$ per cent higher than the state pension and

\section{CAMbridge}


appreciably higher than the official minimum income safety net (after means testing). Morris and colleagues' calculations were for people aged 65 or more years without significant defined disability, and did not include the 40 per cent of the age group with disabilities who, as our study clearly demonstrates, are likely to require additional essential income support and services. Morris et al.'s study provides the first objective benchmark of the income required to enable older people to attain the basic requirements of healthy living, yet the level at which benefits are currently set is wholly inadequate to meet these needs.

The narratives presented in this paper have vividly depicted the consequences of inadequate income in later life, and lend support to the arguments for greater additional resources to meet the costs associated with poor health and disability, particularly for those on low incomes. Research by the Institute for Fiscal Studies has indicated that the proportion of those aged 65 and over living in poverty in the $\mathrm{UK}$ is set to remain at its current level between 2007-08 and 2017-18, viz. around onein-five (Brewer et al. 2007). Moreover, Morris et al.'s (2007) work indicates that the use of the government's definition of relative poverty in official statistics under-estimates the actual numbers of older people who live in poverty and are unable to engage in activities likely to sustain physical and mental wellbeing.

We mentioned in the introduction that the much debated and disputed interface between agency and structure is a feature of the social exclusion debate. Hitherto, the focus of most commentaries has been on the apparent lack of agency with respect to claiming benefits, particularly among older people (Kerr I982; Craig I99I). The findings presented here throw light on the character of the linkage between agency and structure. It was abundantly clear that what has been cast as a failure of agency on the part of older people - to recognise and claim their entitlements for support - is better understood as a structured phenomenon. Other analyses of the interview data reported elsewhere showed that the structure of health and welfare programmes over the lifecourse had influenced older people's propensity to claim, and it took a policy-oriented and quasiexperimental intervention to facilitate the exercise of agency (Moffatt and Higgs 2007).

\section{The effectiveness of the primary healthcare setting}

We turn finally to the effectiveness of a primary healthcare-based welfare rights service in increasing the incomes of older people. The study reported in this paper was drawn from a pilot randomised controlled trial of I $_{2} 6$ respondents, $5^{8}$ per cent of whom received a welfare benefit 
(3 I financial, i6 non-financial and 2I both). Their median weekly financial award was $€ 55$ (€8I, \$98) per household (Mackintosh et al. 2006). Our findings carry important lessons for policy, particularly the effectiveness of welfare-rights services in increasing the incomes of older people and in the relationship between resources and social exclusion among older people. There is considerable evidence from various organisations that benefit take-up campaigns specifically targeted at older people can be highly effective, especially when organisations that promote the interests of older people collaborate with the statutory health and social services. A survey carried out by the Citizens' Advice Bureau (CAB) in 2003 found that 102 Bureaux had carried out take-up campaigns aimed at older people. The estimate of the total gain from previously unclaimed benefits for the clients from the 68 bureaux that gave details was $f_{\mathrm{I}} 3$ million (Citizens Advice Bureau 2003). Some of the most detailed evaluations of effectiveness of take-up initiatives have taken place in health-care settings, usually in conjunction with the $\mathrm{CAB}$ or local authority welfare-rights services (Adams et al. 2006).

Earlier we alluded to the reasons why older people find health settings more acceptable, but there are also many practical reasons why health settings are advantageous to both older people and service providers. Many older people, including the housebound, are in regular contact and well known to health-care practitioners, not least through the preventative services (e.g. winter flu injections), or through ill health, disability or a caring role. Primary health-care centres are therefore appropriate settings in which to make contact with older people, particularly those who are likely to be entitled to health-related social security or care benefits. We do not argue that health-care settings are the only appropriate places in which welfare-rights services should be delivered to older people, but instead suggest that many of their features that lead to increases in their older patients' incomes could be adopted in other settings. These key features are: the active creation of contacts with older people to alert them to their entitlements, pro-active offers of advice to the retired, and particularly those in poor health, with a disability or in a caring role; and active assistance with the process of claiming. These features are largely absent from the national information campaigns that concentrate on encouraging people to seek and claim benefits and which have had inconsistent results and have failed to substantially reduce non-claiming. The 'LinkAge Plus' pilot programme is the British government's most recent initiative to reduce social exclusion among older people (Department for Work and Pensions 2005). Part of the 'Sure Start to Later Life' initiative (Office of the Deputy Prime Minister 2006), a key component is to provide a 'single accessible gateway' to services for older people. An interim

\section{CAMBRIDGE}


evaluation of the LinkAge Plus pilot schemes has shown that there are benefits to older people of accessing services, including increased benefit uptake (Davies and Ritters 2007). It is as yet too early to say whether this strategy has the same success as targeted welfare-rights initiatives in tackling the problems of non-uptake of state benefits, especially since there are no concrete government proposals to reduce the complexity of the benefits system (House of Commons Committee of Public Accounts 2007).

\section{Conclusions}

The small qualitative study reported in this paper has explored the impact of extra resources on older people with low incomes, and provided evidence of the effectiveness of pro-active welfare-rights services in increasing income. The study has shed light on the patterning of social exclusion among older people as sketched by quantitative studies like the PSE Survey, and the discussion has clarified the explanatory potential of concepts like material assets, social assets and social exclusion in relation to quality of life. It has been shown that a weak day-to-day flow of material assets is intimately related to a weak flow of social assets, and has moreover suggested that for many people the relationship is causal. This is not to assert that the relationship is deterministic, that the causality is never reversed, or that the strength of the flows of biological, psychological, cultural and spatial assets cannot be more influential (Scambler 2002). There is a powerful case for further qualitative research, including ethnographic case studies, to clarify just how asset flows known to be efficacious for quality of life and longevity impact on social exclusion.

\section{Acknowledgements}

We thank all the participants and the primary health-care teams for their cooperation with the study. Particular thanks to Rosemary Bell, Jenny Dover and Nick Whitton of Newcastle City Council Welfare Rights Service, and Martin White, Joan Mackintosh, Denise Howel and Adam Sandell of the Institute of Health and Society, Newcastle University. We thank the Department of Health (England) Policy Research Programme that funded the study, Newcastle National Health Service Primary Care Trust and Newcastle City Council Social Services Directorate. We also acknowledge the helpful comments of two anonymous reviewers. The views expressed in this paper are those of the authors and not necessarily those of the Department of Health.

\section{CAMBridge}




\section{NOTES}

I Pension Credit (formerly Minimum Income Guarantee) is a means-tested benefit with two components: Guarantee Pension Credit available to those aged over 6o; Savings Pension Credit available to those aged over 65.

2 The Citizens Advice Bureau is a national charity supported by public funds that runs advice offices in every substantial settlement in the United Kingdom. Age Concern and Help the Aged are national advocacy and representational organisations for older people. The Age Concern movement comprises numerous independent local organisations, again in every county, town and city borough, with national policy co-ordinating bodies in England, Scotland, Wales and Northern Ireland.

3 Permission to carry out the study was obtained from Newcastle and North Tyneside Joint Local National Health Service Research Ethics Committee and from Newcastle NHS Primary Care Trust. The project was registered in accordance with the Data Protection Act.

4 The Attendance Allowance is a non means-tested UK state benefit paid to claimants aged 65 or more years who require frequent attention through the day and night for help with their bodily functions, or continual supervision through the day and/or night to avoid substantial danger to themselves and/or others.

\section{References}

Abbott, S. 2002. Prescribing welfare benefits advice in primary care: is it a health intervention, and if so, what sort? Fournal of Public Health Medicine, 24, 4, 307-12.

Acheson, D. I998. Independent Inquiry into Inequalities in Health. Her Majesty's Stationery Office, London.

Adams, J., White, M., Moffatt, S., Howel, D. and Mackintosh, J. 2006. A systematic review of the health, social and financial impacts of welfare-rights advice delivered in health care settings. BMC Public Health, 6, 8I.

Argyle, E. 200r. Poverty, disability and the role of older carers. Disability and Society, r6, 4 , 585-95.

Atkinson, A. B. 1998. Social exclusion, poverty and unemployment. In Atktinson, A. and Hills, J. (eds), Exclusion, Employment and Opportunity. CASE Paper 4, London School of Economics, London, 9-24.

Barbour, R. S. 200I. Checklists for improving rigour in qualitative research: the case of the tail wagging the dog? British Medical fournal, 322, in I5-7.

Barbour, R. S. 2003. The new found credibility of qualitative research? Tales of technical essentialism and co-option. Qualitative Health Research, 13, 7, I019-27.

Bardasi, E., Jenkins, S. and Rigg, J. 2002. Retirement and the income of older people: a British perspective. Ageing \& Society, 22, 2, I3 ${ }^{-}-59$.

Barnes, M. 2005. Social Exclusion in Great Britain: An Empirical Investigation and Comparison with the EU. Ashgate, Aldershot, Hampshire.

Brewer, M., Browne, J., Emerson, C., Goodman, A., Muriel, A. and Tetlow, G. 2007. Pensioner Poverty over the Next Decade: What Role for Tax and Benefit Reform? Institute for Fiscal Studies, London.

Burchardt, T., Le Grand, J. and Piachaud, D. 2002. Introduction. In Hills, J., Le Grand, J. and Piachaud, D. (eds), Understanding Social Exclusion. Oxford University Press, Oxford, I-I2.

Byrne, D. 2005. Social Exclusion. Open University Press, Maidenhead, Berkshire. 
Chandola, T., Ferrie, J., Sacker, A. and Marmot, M. 2007. Social inequalities in selfreported health in early old age: follow-up of prospective cohort study. BMJ Online First, 27 April. Available online at http://www.bmj.com/cgi/rapidpdf/bmj.39i67.439792. 55Vi [Accessed April 2007].

Citizens Advice Bureau 2003. Serious Benefits: The Success of CAB Benefit Campaigns. Citizens Advice Bureau, London. Available online at http://www.citizensadvice.org.uk/ pdf_serious_benefits.pdf [Accessed June 2007].

Clark, H., Dyer, S. and Horwood, J. I998. 'That Bit of Help': The High Value of Low Level Preventative Services for Older People. Policy Press, Bristol, Avon.

Clayman, S. E. and Maynard, D. W. 1995. Ethnomethodology and conversation analysis. In ten Have, P. and Psathas, G. (eds), Situated Order: Studies in the Social Organisation of Talk and Embodied Activities. University Press of America, Washington DC, I- 30 .

Coppel, D. H., Packham, C. J. and Varnham, M. A. I999. Providing welfare-rights advice in primary care. Public Health, $\mathbf{I} \mathbf{1} 3, \mathrm{I}^{3} \mathrm{I}^{-} 5$.

Corden, A. I999. Claiming entitlements: take-up of benefits. In Ditch, J. (ed.), Introduction to Social Security. Routledge, London, I34-55.

Costigan, P., Finch, H., Jackson, B., Legard, R. and Ritchie, J. I999. Overcoming Barriers: Older People and Income Support. Research Report, Department of Social Security, London.

Craig, P. 1991. Costs and benefits: a review of research on take-up of income related benefits. Fournal of Social Policy, 2o, 4, 537-65.

Craig, G. 2004. Citizenship, exclusion and older people. Fournal of Social Policy, 33, I, 95-II4.

Davies, H. and Ritters, K. 2007. LinkAge Plus National Evaluation Team Interim Findings. Department for Work and Pensions, London. Available online at http://www.dwp. gov.uk/asd/asd5/WP42interim.pdf [Accessed 8 January 2008].

Department for the Environment, Transport and the Regions 200o. Measuring Multiple Deprivation at the Small Area Level: The Indices of Deprivation 200o. Department for the Environment, Transport and the Regions, London.

Department for Work and Pensions 2006. Income Related Benefits: Estimates of Take-up in 2003-2004. Department for Work and Pensions, London. Available online at http://www.workandpensions.gov.uk/asd/income_analysis/finalozo4.pdf [Accessed October 2006].

Department for Work and Pensions 2002. Households Below Average Income (HBAI) Series 1994/ 05-200o/оI. Department for Work and Pensions, London. Available online at http://www.dwp.gov.uk/asd/hbai/hbai2oor/contents.asp [Accessed May 2006].

Department for Work and Pensions 2005. Opportunity Age: Opportunity and Security Throughout Life. Stationery Office, London. Available online at http://www.dwp.gov.uk/ opportunity_age/linkage [Accessed September 2007].

Evandrou, M. and Glaser, K. 2004. Family, work and quality of life: changing economic and social roles throughout the lifecourse. Ageing \& Society, 24, 5, 77I-9I.

Gilleard, C. and Higgs, P. 2005. Contexts of Ageing: Class, Cohort and Community. Polity, Cambridge.

Ginn, J. 2003 a. Gender, Pensions and the Lifecourse: How Pensions Need to Adapt to Changing Family Forms. Policy Press, Bristol, Avon.

Ginn, J. 2003 . Parenthood, partnership status and pensions: cohort differences among women. Sociology, 37, 3, 493-510.

Gordon, D., Levitas, R., Pantazis, C., Patsios, D., Payne, S., Townsend, P., Adelman, L., Ashworth, K., Middleton, S., Bradshaw, J. and Williams, J. 2000. Poverty and Social Exclusion in Britain. Joseph Rowntree Foundation, York. Available online at http://www.jrf.org.uk/bookshop/eBooks/I85935I28X.pdf [Accessed January 2006].

\section{CAMBridge JDURNALS}


Higgs, P. 1997. Citizenship theory and old age: from social rights to surveillance. In Jamieson, A., Harper, S. and Victor, C. (eds), Critical Approaches to Ageing and Later Life. Open University Press, Buckingham, i $18-3$ I.

Hills, J. and Stewart, K. (eds) 2007. A More Equal Society? New Labour, Poverty, Inequality and Exclusion. Policy Press, Bristol, Avon.

Hills, J., Le Grand, J. and Piachaud, D. (eds) 2002. Understanding Social Exclusion. Oxford University Press, Oxford.

Hoskins, R. and Smith, L. 2002. Nurse-led welfare benefits screening in a general practice located in a deprived area. Public Health, I $16,214^{-20 .}$

Hoskins, R., Tobin, J., McMaster, K. and Quinn, T. 2005. Roll-out of a nurse-led welfare benefits screening service throughout the largest local health care co-operative in Glasgow: an evaluation study. Public Health, r 1 9, 853-6r.

House of Commons Committee of Public Accounts (HCCPA) 2007. Department for Work and Pensions: Using Leaflets to Communicate with the Public About Services and Entitlements. Seventh Report of Session 2006-07, HCCPA, Stationery Office, London. Available online at http://www.publications.parliament.uk/pa/cm200607/cmselect/cmpubacc/133/r33. pdf [Accessed March 2007].

Kerr, S. 1982. Deciding about supplementary pensions: a provisional model. Fournal of Social Policy, I I, 4, 505-17.

Mackintosh, J., White, M., Howel, D., Chadwick, T., Moffatt, S., Deverill, M. and Sandell, A. 2006. Randomised controlled trial of welfare-rights advice accessed via primary health care: pilot study. BMC Public Health, 6, I62 [ISRCTN61522618].

Marmot, M. and Nazroo, J. 200I. Social inequalities in health in an ageing population. European Review, 9, 445-6o.

Mayhew, V. 2002. Barriers to take up among older people: a summary of the research. In Fleiss, A. (ed.), Social Research Yearbook 2000/200I. Department for Work and Pensions, London, 57-65.

Mays, N. and Pope, C. 2000. Quality in qualitative health research. In Pope, C. and Mays, N. (eds), Qualitative Research in Health Care. BMJ Books, London, 89-10г.

Moffatt, S., Mackintosh, J., White, M., Howel, D. and Sandell, A. $2006 a$. The acceptability and impact of a randomised controlled trial of welfare-rights advice accessed via primary care: qualitative study. BMC Public Health, 6, г63.

Moffatt, S., White, M., Mackintosh, J. and Howel, D. 2006 b. Using quantitative and qualitative data in health services research: what happens when mixed-method findings conflict? BMC Health Services Research, 6, 28 [ISRCTN6I5226I8].

Moffatt, S. and Higgs, P. 2007. Charity or entitlement? Generational habitus and the welfare state among older people in North East England. Social Policy and Administration, 4I, 5, 449-64.

Morris, J., Wilkinson, P., Dangour, A. D., Deeming, D. and Fletcher, A. 2007. Defining a minimum income for healthy living (MIHL): older age, England. International fournal of Epidemiology, 54, I2, 885-9.

National Audit Office 2002. Tackling Pensioner Poverty: Encouraging Take-up of Entitlements. Report by the Comptroller and Auditor General, House of Commons 37 Session 2002-2003, November 2002. National Audit Office, London. Available online at http:// www.nao.org.uk/publications/nao_reports/02-03/o20337.pdf [Accessed January 2003].

Office of the Deputy Prime Minister 2006. A Sure Start to Later Life: Ending Inequalities for Older People. Stationery Office, London.

Office of National Statistics (ONS) 200I. General Household Survey 200I. ONS, London. Available online at http://www.data-archive.ac.uk/findingData/snDescription.asp? sn $=4646$ [Accessed January 2002].

Pantazis, G., Gordon, D. and Levitas, R. (eds) 2006. Poverty and Social Exclusion in Britain: The Millennium Survey. Policy Press, Bristol, Avon.

\section{CAMBridge}


Paris, J. A. G. and Player, D. 1993. Citizens advice in general practice. British Medical Fournal, 306, I518-20.

Patsios, D. 2006. Pensioners, poverty and social exclusion. In Pantazis, C., Gordon, D. and Levitas, R. (eds), Poverty and Social Exclusion in Britain: The Millennium Survey. Policy Press, Bristol, Avon, 43 ${ }^{-}{ }^{-8}$.

Phillipson, C. and Scharf, T. 2004. The Impact of Government Policy on Social Exclusion Among Older People. Office of the Deputy Prime Minister, London.

Prescott-Clarke, P., Primatesta, P., Bost, L., Dong, W., Hedges, B., Prior, G., Purdon, S. and di Salvo, P. 1997. Health Survey for England 1995. Stationery Office, London.

Price, D. and Ginn, J. 2006. The future of inequalities in retirement income. In Vincent, J., Phillipson, C. and Downs, M. (eds), The Futures of Old Age. Sage, London, 76-84.

QSR International 2000. NVivo Version 2.I. QSR International Australia, Melbourne, Victoria. Available online at www.scolari.co.uk/qsr/qsr_nvivo.html [Accessed June 2003].

Ritchie, J. and Lewis, J. (eds) 2003. Qualitative Research Practice: A Guide for Social Scientists. Sage, London.

Scambler, G. 2002. Health and Social Change: A Critical Theory. Open University Press, Buckingham, Buckinghamshire.

Scharf, T., Phillipson, C. and Smith, A. 2005. Multiple Exclusion and Quality of Life Amongst Excluded Older People in Disadvantaged Neighbourhoods. Social Exclusion Unit, Office of the Deputy Prime Minister, London.

Scharf, T., Bartlam, B., Hislop, J., Bernard, M., Dunning, A. and Sim, J. 2006. Necessities of Life: Older People's Experiences of Poverty. Help the Aged, London.

Seale, C. I999. The Quality of Qualitative Research. Blackwell, Oxford.

Silver, H. I994. Social exclusion and social solidarity: three paradigms. International Labour Review, 133, 53 ${ }^{\mathrm{I}-78}$.

Silverman, D. 200o. Doing Qualitative Research. Sage, London.

Smith, N., Middleton, S., Ashton-Brooks, K., Cos, L., Dobson, B. and Reith, L. 2004. Disabled People's Costs of Living: More Than You Would Think. Joseph Rowntree Foundation, York.

Social Exclusion Unit 2005. Excluded Older People. Interim Report, Social Exclusion Unit, Office of the Deputy Prime Minister, London.

Toynbee, P. 2004. We cannot allow the poor to fall into the pensions abyss. The Guardian (London), October I3, page 24 .

Victor, C. 2005. The Social Context of Ageing: A Textbook of Gerontology. Routledge, London.

Walker, A. and Walker, C. (eds) i997. Britain Divided. Child Poverty Action Group, London.

Wanless, D. 2004. Securing Good Health for the Whole Population. Final Report to The Treasury, Stationery Office, London. Available online at http://www.hm-treasury.gov.uk/consultations_and_legislation/wanless/consult_wanlesso4_final.cfm [Accessed May 2004].

Accepted I7 December 2007

Address for correspondence:

Suzanne Moffatt, Public Health Research Programme, Institute of Health and Society, Newcastle University, Newcastle-upon-Tyne, NE2 ${ }_{4} \mathrm{HH}$, UK.

E-mail: s.m.moffatt@ncl.ac.uk 